Recombinant Human Erythropoietin for Anemia of EndStage Renal Failure in Beta Thalassemia Trait

\begin{tabular}{|l|l|l|}
\hline A. & Alexander & Kagan $^{\mathrm{a}}$ \\
\hline L. & Levana & Sinay-Trieman $^{\mathrm{a}, \mathrm{b}}$ \\
\hline Y. & Yaacov & Bar-Khayim $^{\mathrm{a}}$ \\
\hline
\end{tabular}

${ }^{\mathrm{a} D i v i s i o n}$ of Nephrology and ${ }^{\mathrm{b}}$ Department of Pediatrics B, Kaplan Hospital, Rehovot, Israel

A. Kagan, MD, Division of Nephrology, Kaplan Hospital, Rehovot, 76100 (Israel)

Dear Sir,

Recently, Steinberg [1] reported the successful use of recombinant human erythropoietin in the treatment of 2 patients with sickle cell anemia and renal failure. We have used erythropoietin therapy for severe anemia in 2 siblings with $\beta$ thalassemia minor and end-stage renal failure, in whom a unique association of hereditary nephritis and ep-idermolysis bullosa was previously reported [2].

The hematological characteristics of the patients and their response to treatment are shown in figure 1. Blood transfusion requirements for 6 months prior to therapy were 14 blood units for R.Y., a 21-year-old male, and 12 blood units for I.Y., his 19-year-old sister. In the first 4 months following initiation of erythropoietin treatment, R.Y. required 7 units and I. Y. 5 units; thereafter, blood transfusions were not needed. No problems with vascular access or increase in blood pressure were observed. Maintenance doses of erythropoietin in 15 other adult patients on dialysis are shown in table 1 . These doses in the 2 siblings were higher than those required in the other 6 patients with $\beta$ thalassemia trait, probably due to the differences in the $\beta$ globin synthesis.

$\beta$ Thalassemia is characterized by a decreased amount of $\beta$ globin as well as typically

\title{
110
}

2452452450367490490490490490

! I ! I I I 1 I ! I

R.Y.

$-100 \mathrm{~m}$

Q.

$\mathrm{P}$

\section{$590 \prod$}

Fig. 1. Response of hemoglobin to recombinant erythropoietin in 2 siblings with $\beta$ thalassemia minor undergoing dialysis. Arrows above the graph indicate the doses of erythropoietin (in U/kg/week) in R.Y. (127 months on hemodialysis; $\bullet$ ), and arrows below the graph indicate the doses of erythropoietin in I. Y. (21 months on continuous ambulatory peritoneal dialysis and 60 months on hemodialysis; $\mathrm{O}$ ). The bars indicate the blood 
transfusion units per month. The insert records the hematological characteristics of the 2 siblings prior to erythropoietin treatment.

$$
-80
$$

$\mathrm{m}$

o

$\overline{0}^{1}$

o 70

$\mathrm{X}$

$60-$

I I I 1 I I I i 1 I I 1

I.Y.

3161581580316316474474474474

$-\mathrm{t}-10$

MONTHS

(C) 1992 S.KargerAG, Basel

$0028-2766 / 92 /$

0622-0229S2.75/0

Table 1. Maintenance doses of recombi-nant human erythropoietin in patients with and without $\beta$ thalassemia trait undergoing chronic hemodialysis

high endogenous erythropoietin levels [3] that decline during the course of the disease [4]. It is possible that the ability of the marrow to respond to erythropoietin in these patients is impaired [5], especially if the disease is accompanied by chronic renal failure which is associated with low erythropoietin levels [6]. Therefore, in patients with $B$ thalassemia and end-stage renal failure, anemia is likely to be more pronounced.

It was recently shown that an average increase in hemoglobin can be achieved in patients with $B$ thalassemia intermedia by administration of high doses of erythropoietin [7]. Moreover, recombinant human erythropoietin effectively reverses anemia in patients undergoing dialysis [8]. We believe that resistant anemia associated with $\beta$ thalassemia and end-stage renal disease may be treated successfully with high doses of erythropoietin.

References

Steinberg MH: Erythropoietin for anemia of renal failure in sickle cell disease. $\mathrm{N}$ Engl J Med 1991;324:1369-1370.

Kagan A, Feld S, Chemke J, Bar-Khayim Y: Occurrence of hereditary nephritis, pretibial epidermolysis bullosa and beta thalassemia minor in two siblings with end-stage renal disease.

Nephron 1988;49:331-332.

Shannon KM: Recombinant erythropoietin in pediatrics: A clinical perspective. Pediatr Ann 1990;19:197-206. 
Manor D, Fibach E, Goldfarb A, Rachmilewitz EA: Erythropoietin activity in the serum of beta thalassemic patients. Scand J Haematol 1986; 37:221-228.

Cavill I, Ricketts C, Jacobs A, Letsky E: Erythropoiesis and the effect of transfusion in homozygous ß-thalassemia. N Engl J Med 1978; 298: 776-778.

Eschbach JW: The anemia of chronic renal failure: Pathophysiology and the effects of recombinant erythropoietin. Kidney Int 1989;35:134-148.

Rachmilewitz EA, Goldfarb A, Dover G: Increase in RBC, Hb and hematocrit following administration of erythropoietin to patients with beta thalassemia intermedia (abstract). Blood 1990;76(suppl. 1):283.

Sinay-Trieman L, Salusky IB, Fine RN: Use of subcutaneous erythropoietin in children undergoing continuous cycling peritoneal dialysis. J Pediatr 1989;114:550-554.

230

Kagan/ Sinay-Trieman/ Bar-Khayim

Erythropoietin for Anemia of End-Stage Renal Failure in $ß$ Thalassemia 